\title{
घरेलु महिलाओं के उच्च रक्तचाप स्तर पर योगाभ्यास के प्रभाव का अध्ययन
}

गायत्री गुर्वेन्द्र एवं अमृत गुर्वेन्द्र

सारांश

प्रस्तुत शोधका मुख्य उद्देश्य 'घरेलु महिलाओं के उच्चरक्तचाप स्तर पर योगाभ्यास के प्रभाव का अध्ययन' है। इस शोध अध्ययनमें 'पूर्व-पश्चात् परीक्षण एकल समूह' शोध अभिकल्प का प्रयोग किया गया। आकस्मिक प्रतिचयन विधि द्वारा हरिद्वार (उत्तराखण्ड) क्षेत्र से30-40आयु वर्ग की 26 महिलाओं का चयन किया गया। उच्चरक्तचाप स्तर को मापने के लिए 'स्फेग्मोमेनोमीटर व स्टेथेस्कोप' का प्रयोग किया गया। प्रयोज्यों को एक माह तक प्रतिदिन 60 मिनट तक निर्धारित योगाभ्यास समूह का अभ्यास कराया गया। प्राप्त आंकड़ों का सांख्यिकीय विश्लेशण 'टी-परीक्षण' द्वारा किया तथा 'टी' का मान 0.01 स्तर पर सार्थक पाया गया जिससे यह निष्कर्ष निकलता है कि घरेलु महिलाओं के उच्चरक्तचाप स्तर पर योगाभ्यास का सकारात्मक प्रभाव पड़ता है।

कूटशब्द : उच्चरक्तचाप,घरेलु महिलाएँ एवं योगाभ्यास।

स्वास्थ्य समस्याओं में वर्तमान समय में उच्च रक्तचाप एक महत्वपूर्ण समस्या है, जिससे लगभग 5.10 :वयस्क प्रभावित है। अनियन्त्रित उच्च रक्तचाप से व्यक्ति के मस्तिश्क, हृदय, आँख, गुर्दे एवं शरीर की प्रमुख धमनियों पर बुरा प्रभाव पड़ता है। दवा एवं परहेज के द्वारा उच्च रक्तचाप को नियन्त्रित करके इससे सम्बन्धित जटिलताओं को कम किया जा सकता है (चौहान2011)। आधुनिक औद्योगिक युग की देन तनावपूर्ण जीवन के चलते उच्च रक्तचाप सामान्य रोगों की श्रेणी में गिना जाने लगा है। इस रोग के कारण धीरे-धीरे व्यक्ति मृत्यु की ओर अग्रसर होता रहता है। भारत देश में हाई ब्लड प्रेशर एक आम रोग हो गया है। 30 वर्ष की उम्र के पश्चात् 10 में से एक व्यक्ति इस रोग का शिकार होता है और इनमें 90 प्रतिशत लोगों में इस रोग का निदान ही नहीं हो पाता क्योंकि वर्षों तक यह रोग शरीर में लक्षण रहित हो सकता है। अक्सर इस रोग का निदान तब होता है जब रोगी को किसी और रोग के लिए जांच कराना होता है (पीयूष 2011)। सिर में दर्द चक्कर आना, बेहोशी, नक्सीर, आँखों में धुंधलापन, छाती में दर्द, सांस लेने में परेशानी, धड़कन व कानों में सांय-सांय की आवाज इत्यादि इस रोग के चेतावनी देने वाले लक्षण है।

उच्चरक्तचाप के जितने भौतिक कारण है, उतने ही भावनात्मक कारण भी है। चिन्ता एवं परेशानियों से अत्यधिक तनावग्रस्त मन एक असन्तुलित मानसिकता को जन्म देता है, जो लगातार क्रोध, भय एवं दुःख के उतार-चढ़ाव के झूले में झूलती रहती है। ये उद्वेग हमारे शरीर में स्थित अनुकम्पी तन्त्रिका प्रणाली को अनियन्त्रित रूप से उत्प्रेरित करते हैं। इस उत्प्रेरणा के फलस्वरूप रक्त में उत्तेजक हॉरमोन्स एड्रीनलीन एवं नॉरएड्रीनलीन की मात्रा अत्यधिक बढ़ जाती है। इनके प्रभाव से हृदय को अपने सामान्य गति से अधिक बार धड़कने के लिए
बाध्य होना पड़ता है, जिससे रक्तचाप स्तर में वृद्धि हो जाती है (सरस्वती 2003)।

व्यक्तिगत सम्बन्धों से उपजे तनाव, जो हमारी भावनाओं, प्रवृत्तियों एवं इच्छाओं के टकराने से उत्पन्न होते हैं, वे हमारे हृदय एवं अन्तःस्रावी तन्त्र पर लगातार दबाव डालते रहते हैं। इस दबाव तथा अनुकंपी तन्त्र की अतिक्रियाशीलता के कारण सम्पूर्ण शरीर की छोटी-छोटी रक्त वाहिनियाँ अनवरत आकुंचन की अवस्था में पहुँच जाती हैं। इसके कारण हृदय को उनमेंसे रक्त प्रवाहित करने में अधिक जोर लगाना पड़ता है तथा बहने वाले रक्त का दबाव बढ़ जाता है।कुछ वर्षों पहले तक चिकित्सा शास्त्री यह मानते थे कि इन सबका कारण कोरोनरी संवहनी में खून के थक्के जमना तथा रक्त प्रवाह अवरूद्ध होना है। जबकि वर्तमान शोध निष्कर्ष में प्रवाहवरोध का कारण संवहनियों के अतिआकुंचन या ऐंठन कोपाया गया। यह ऐंठन तीव्र भावनात्मक प्रतिक्रिया के फलस्वरूप अनुकम्पी तन्त्र की अतिक्रियाशीलता से होती है (सरस्वती 2003)।

योग विज्ञान मनुष्य की सभी आवश्कताओं को पूरा करते हुए मानवीय चेतना की अन्तर्शक्तियों को जागृत एवं सुविकसित करता है।'योग' शब्द का अर्थ है 'सम्मिलित होना या एक होना"इस एकीकरण का अर्थ मनुष्य के व्यक्तित्व के शारीरिक, मानसिक, बौद्धिक तथा आध्यात्मिक पक्षों के एकीकरण से हैं। आधुनिक योग दर्शन एवं साधना कुछ महान भारतीय विचारकों एवं उद्देश्यों की देन हैं (वर्णवाल, 2002)।

वर्तमान समय में बढ़ती हुई मानसिक तथा शारीरिक अस्वस्थता का निवारण एक मात्र योग में निहित हैं। "आज की ज्वलन समस्या मानसिक रोगों की हैं। जिसके कारण चिन्ता, तनाव, उच्च रक्त चाप बढ़ता जा रहा है। साथ में मोटापा भी बढ़ रहा है। ऐसे व्यक्तियों को यौगिक क्रियाएँ तथा ध्यान कराने के 
पश्चात, उच्च रक्त चाप की कमी तथा मानसिक अस्वस्थता में काफी कमी पाई (गुप्ता, 2002)।

योग विज्ञान के अनुसार तनाव ग्रस्त तथा हृदय रोग से पीड़ित व्यक्तियों के लिए अपने भावनात्मक ढाँचे की संरचना तथा उसके हृदय व मन पर पड़ने वाले प्रभावों को पहचानना एवं समझना अत्यन्त आवश्यक है। सूक्ष्म व्यायाम व योगाभ्यास की संपूर्ण वैज्ञानिक प्रक्रिया द्वारा निपुणता हासिल करना इस दिशा में पहला कदम होगा, क्योंकि हृदय रोगी अक्सर अपनी भावनात्मक स्थितियों द्वारा अधिक प्रभावित होते हैं। हालाँकि सतही तौर पर वे कितने ही शांत, सौम्य एवं सुदृढ व्यक्तित्व के मालिक हों, उनका अवचेतन तो संवेदनशील रहता ही है। दमित भावनाएँ, जो वर्षों तक भीतर ही भीतर सड़ती रही हों और उनकी अभिव्यक्ति शर्म, कुण्ठा या अस्वीकृति के कारण नहीं हो पाई हो, वे अन्दर ही अन्दर अवचेतन तनाव में परिवर्तित हो हृदय रोग के रूप में अभिव्यक्त होती हैं। योग के अभ्यास से व्यक्ति धीरे-धीरे अपने अन्तश्चेतन के गह्नर से इन दमित वासनाओं, असुरक्षाओं तथा भावनात्मक जटिलताओं को मुक्त करने में सफल होता है (सरस्वती 2003)।

शोध विधि

प्रस्तुत शोध में शोधार्थी ने घरेलु महिलाओं के उच्चरक्तचाप स्तर पर योगाभ्यास के प्रभाव का अध्ययन किया है। इस शोध द्वारा यह जानने का प्रयास किया गया है कि योगाभ्यास उच्चरक्तचाप स्तर को कम करने में कहाँ तक सहायक है।

योगाभ्यास समूह सारणी -

\begin{tabular}{|c|l|c|c|}
\hline $\begin{array}{c}\text { क्र. } \\
\text { सं. }\end{array}$ & \multicolumn{1}{|c|}{ योगाभ्यास } & चक्र & समय \\
\hline 1 & पवनमुक्तासन भाग 1 & 15 & 10 मिनट \\
\hline 2 & वज्ञासन & 3 & 2 मिनट \\
\hline 3 & शशांकासन & 3 & 2 मिनट \\
\hline 4 & सर्पासन & 3 & 2 मिनट \\
\hline 5 & योगमुद्रासन & 3 & 2 मिनट \\
\hline 6 & गोमुखासन & 3 & 2 मिनट \\
\hline 7 & शवासन & 1 & 5 मिनट \\
\hline 8 & ध्यानात्मकासन (सिद्ध,स्वस्तिक,पद्म) & 1 & प्राणायाम, मुद्रा \\
& & & $\begin{array}{c}\text { एवं ध्यान के पूरे } \\
\text { समय। }\end{array}$ \\
\hline 9 & नाड़ीशोधन,उज्जायी & 8 & 9 मिनट \\
\hline 10 & योगनिद्रा & 1 & 10 मिनट \\
\hline 11 & हृदयमुद्रा & 1 & 8 मिनट \\
\hline 12 & सोडमम ध्यान & 1 & 8 मिनट \\
\hline & \multicolumn{2}{|c|}{ कुल } & मिनट \\
\hline
\end{tabular}

प्रतिदर्श एवं प्रतिचयन

प्रस्तुत शोध अध्ययन में आकस्मिक प्रतिचयन विधि द्वारा हरिद्वार (उत्तराखण्ड) से 30 से 40 आयु वर्ग की 26 महिलाओं का चयन किया गया।

शोध अभिकल्प

प्रस्तुत शोध अध्ययनमें 'पूर्व-पश्चात् परीक्षण एकल समूह'

शोधअभिकल्प का प्रयोग किया गया है।

शून्य परिकल्पना

घरेलु महिलाओं के उच्चरक्तचाप स्तर पर योगाभ्यास का कोई सार्थक प्रभाव नहीं पड़ता।

चरों का विवरण

स्वतंत्र चर- योगाभ्यास समूह।

आश्रित चर- उच्चरक्तचाप।

अन्य चर - आयु (30-40वर्ष)।

उपकरण-

प्रस्तुतशोध मेंउच्चरक्तचाप स्तर को मापने के लिए 'स्फेग्मोमेनोमीटर व स्टेथेस्कोप' का प्रयोग किया गया।

विधि

प्रस्तुत शोध अध्ययन में 'पूर्व-पष्चात् परीक्षण एकल समूह' शोध अभिकल्प का प्रयोग किया गया।जिसमें 26 महिला प्रयोज्यों का चयन आकस्मिक प्रतिचयन विधि द्वारा किया गया। प्रयोज्यों को योगाभ्यास कराने के पूर्व 'स्फेग्मोमेनोमीटर व स्टेथेस्कोप' के द्वारा परीक्षण किया गया। तदुपरान्त 30 दिन तक निर्धारित योगाभ्यास समूह का अभ्यास कराया गया। निर्धारित समयावधि तक यौगिक अभ्यास कराने के पष्चात् 'स्फेग्मोमेनोमीटर व स्टेथेस्कोप' के द्वारा इन्हीं प्रयोज्यों का पुनः परीक्षण किया गया। तद्पष्चात् प्राप्त आंकड़ों के सांख्यिकीय विश्लेषण हेतु टी-परीक्षण का उपयोग किया गया।

सांख्यिकीय विश्लेषण

प्रस्तुत षोध में आंकड़ों के सांख्यिकीय विष्लेशण हेतु टी-परीक्षण का उपयोग किया गया। 


\section{परिणाम}

सारणी -Systolic एवं Diastolic Pressure का Pre एवं Post के मध्य तुलना।

\begin{tabular}{|l|c|c|c|c|c|c|c|c|c|}
\hline & Test & $\mathbf{N}$ & Mean & SD & $\mathbf{S E}_{\mathbf{D}}$ & $\mathbf{r}$ & $\mathbf{d f}$ & $\mathbf{t}$ - value & Level of significance \\
\hline \multirow{2}{*}{ Systolic } & Pre & 26 & 156.92 & 17.3 & 4.02 & 0.20 & 25 & 9.11 & .01 \\
\cline { 2 - 8 } & Post & 26 & 120.31 & 10.98 & & & & & \\
\hline \multirow{2}{*}{ Diastolic } & Pre & 26 & 107 & 10.50 & 1.17 & 0.79 & 25 & 27.19 & .01 \\
\cline { 2 - 7 } & Post & 26 & 75.19 & 5.97 & & & & & \\
\hline
\end{tabular}

परिणाम सारणी से ज्ञात होता है कि सिस्टोलिक दाब के पूर्व एवं पश्चात् परीक्षण का मध्यमान 156 प92एवं 120.31 है जिसका मानक विचलन 17.3 व 10.98 है मानक त्रुटि विचलन 4.02 तथा सहसंबंध 0.20 है, प्राप्त टी मूल्य 9.11 है जो सांख्यिकीय रूप से 0.01 स्तर पर सार्थक है। जबकि डायस्टोलिक दाब के पूर्व एवं पश्चात् परीक्षण का मध्यमान 107 एवं 75.19 है जिसका मानक विचलन 10.50 व 5.97 है मानक त्रुटि विचलन 1.17 तथा सहसंबंध 0.79 है, टी मूल्य 27.19 है जो सांख्यिकीय रूप से 01 स्तर पर सार्थक है। प्राप्त परिणामों के आधार पर यह कहा जा सकता है कि घरेलु महिलाओं के उच्चरक्तचाप स्तर पर योगाभ्यास का सार्थक प्रभाव पड़ता है।

परिणामों की विवेचना

व्यक्तिगत सम्बन्धों से उपजे तनाव, जो हमारी भावनाओं, प्रवृत्तियों एवं इच्छाओं के टकराने से उत्पन्न होते हैं, वे हमारे हृदय एवं अन्तःस्यावी तन्त्र पर लगातार दबाव डालते रहते हैं। इस दबाव तथा अनुकंपी तन्त्र की अतिक्रियाशीलता के कारण सम्पूर्ण शरीर की छोटी-छोटी रक्त वाहिनियाँ अनवरत आकुंचन की अवस्था में पहुँच जाती हैं। इसके कारण हृदय को उनमें से रक्त प्रवाहित करने में अधिक जोर लगाना पड़ता है तथा बहने वाले रक्त का
दबाव बढ़ जाता है। इसे ही हम उच्चरक्तचाप या हाइपरटेंशन कहते हैं।

ध्यानात्मक आसन मेरूदण्ड की स्थिरता को बनाए रखते हैं तथा प्रजनन हार्मोन्स के स्राव को नियन्त्रित करते हैं। साथ ही रक्त को रीढ़ की हड्डी के निचले भाग पेट की ओर संचारित कर कटिप्रदेश श्रोणि प्रदेश तथा आमाशय के अंगों में सामंजस्य लाते हैं। जिससे अंग शिथिल होकर रक्तचाप पर नियन्त्रण प्राप्त करता है (सरस्वती 2004)। नाड़ीशोधन प्राणायाम में व्यक्ति श्वास प्रश्वास के माध्यम से सकारात्मक विचारों को अपने अंदर प्रविष्ट कराता है तथा नकारात्मक भावों को बाहर निकालता है, जिससे मानसिक शांति बढ़ती है और रक्तचाप स्तर में कमी आती है (डनतजप, 2000)। प्राणायाम का मौलिक सम्बन्ध श्वसन संस्थान से होने के कारण इसके अभ्यास से स्नायु संस्थान में र्थिरता एवं मानसिक शांति प्राप्त होती है। जिससे रक्तचाप में स्थिरता आती है (सरस्वती 2006)।

ध्यान के निरन्तर अभ्यास से शरीर व मन की क्रियाशीलता में वृद्धि होती है जिससे तनाव व विषाद से छुटकारा मिलता है। क्षोभावस्था के विपरीत ध्यानावस्था में आक्सीजन के उपयोग से तथा कार्डियेक आउटपुट से रक्तचाप में कमी आती है (सरस्वती 2004)। डॉ. दाते व अन्य सहयोगियों ने यह पाया है कि 
उच्चरक्तचाप के रोगियों में योग निद्रा के अभ्यास से रक्तचाप निश्चित रूप से कम होता पाया गया है।

उच्चरक्तचाप को शवासन के द्वारा पूर्ण रूप से कम किया जा सकता है। शवासन से सिम्पेथैटिक नर्वससिस्टम शिथिलीकरण को प्राप्त होता है। जिसके कारण सिम्पेथैटिक तनाव में कमी आती है और पैरीफेरल रेजिस्टेन्स घटने से रक्तचाप कम होता है (सरस्वती, 2004)।

\section{निष्कर्ष}

उपरोक्त परिकल्पना के परीक्षण व सांख्यकीय विश्लेषण से प्राप्त परिणामो की विवेचना से स्पष्ट है कि निर्धारित योगाभ्यासों का घरेलु महिलाओं के उच्चरक्तचाप स्तर सकारात्मक व सार्थक प्रभाव पड़ता है इस प्रकार यह कह सकते हैं कि यदि इन योगाभ्यासों का अभ्यास आगे कराने जारी रखा जाय तो घरेलु महिलाओं के उच्चरक्तचाप की समस्या से निजात पायी जा सकती है।

गायत्री गुर्वेन्द्र, पी-एच०डी०, सहायक प्राध्यापक; अमृत गुर्वेन्द, पी-एच०डी०, सह-प्राध्यापक, योग एवं स्वास्थ्य विभाग, देव संस्कृति विश्वविद्यालय, हरिद्वार, भारत।

\section{सन्दर्भ सूची}

सिंह, आर. (1999) योग विज्ञान एवं यौगिक चिकित्सा', दिल्ली : चौखम्बा संस्कृत प्रतिष्ठान, पृ.सं. 4,5

चौहान, जहान सिंह (2011). 'क्लीनिकल डॉयग्नोसिस एण्ड ट्रीटमैन्टस' सुमित प्रकाषन आगरा बी. 91 / ए पृ. सं. 938 ।

वर्णवाल, एस. (2002).' योग और मानसिक स्वास्थ्य,' नई दिल्ली : न्यू भारतीय बुक कॉपारेशन, पृ.सं. 34-39

मिश्र, डी. पी. (2004).'योग और मानसिक स्वार्थ' लखनऊ : न्यूॉयल बुक कम्पनी, पृ. 5-10

गुप्ता, एन. (2002).' स्वस्थ किशोरावस्था की ओर' नई दिल्ली: वोलेन्द्री हैल्थ एसोसीएशन ऑफ इण्डिया, पृ.सं. 2-5

सरस्वती, एस. एस. (2006).'ध्यान योग', उत्तरांचलः द डिवाइन लाइफ सोसायटी, पृ.सं.- 68

सरस्वती स्वामी निरंजनानन्द(2004). 'घेरण्ड संहिता', योग पब्लिकेशन्स ट्रस्ट बिहार, पृ. 154,355-357

सरस्वती, स्वामी सत्यानन्द (2006). 'आसन प्राणायाम मुद्रा बन्ध', योग पब्लिकेषन्स ट्रस्ट, मुंगेर, बिहार, भारत, पृ. 383

सरस्वती, स्वामी सत्यानन्द (2003).' रोग और योग', योग पब्लिकेषन्स ट्रस्ट, मुंगेर, बिहार, भारत,
ब्रह्मवर्चस, (1993).' प्राणायाम से अधिव्याधि निवारण', मथुरा:युग निर्माण योजना, पृ.सं. $155-14$

गोरे, एम.एम. (2004).'शरीर विज्ञान और योगाभ्यास', पुणे; कैवल्य धाम लोनावाला

जैन पीयुष (2004). 'षरीर रचना एवम् क्रिया विज्ञान', खेल साहित्य केन्द, पृ. सं. -70

Dave, M. \& Bhale, M.V. (1989).Effect of Pranav Japa Part-II Understanding Pys 1/29 in the light of personal experience; Yoga Mimamasa, Vol. 28, No. -1, pp. 8-17.

Joshi, B.P. (2003).Physiological \& Psychological effect of yogic pranayam practices: DSVV, www.org, Retrieved on 2003.12.19

Murti, S. (2000).Effect of Om chanting \& Bhramri Pranayama on Mental Health. Yog Mimansa ,31(1)pp. 21-35.

Raturi, S. (2004).Effect of Pranavjapa on Stress \& Anxiety: Dev Sanskriti Inter Disciplinary Journal of Behaviour Sciences \& Oriental studies, Vol. -2.

Shukla, P. (2007).Effect of Pranakarsan Pranayama on mental and physical health: Inter -national conf. on Yoga and health awareness in modern scenario, Gurukul Kangri Uni.

Sirohi, R. (2003). Effect of Nadisadhan Pranayam on forced vital capacity; DSVV, www.org Retrieved on 2003,12.05 